agent failed in trials, but had the same hair loss side effect associated with other chemotherapy drugs. During this period, Cyrus Bacchi, from Pace University, New York, noticed that DFMO showed marked anti-trypanosome activity in animals, and in 1983, Belgian physician Henri Taelman used the renamed eflornithine to treat a comatose woman in Antwerp. She began to revive within a day, earning eflornithine the soubriquet "the resurrection drug."

However, set against the backdrop of war, economic deterioration and collapse of rural health infrastructure in countries such as Angola, Congo and Sudan, the potential of eflornithine to mitigate HAT suffering languished. This, combined with eflornithine's difficult administration procedure-it requires two-week hospitalization and continuous IV infusions, requirements difficult to satisfy in HAT-endemic regions-means that the compound had no real revenue value for pharmaceutical companies. In 1995, Aventis halted its production, along with that of two other drugs for HAT. Simultaneously, Bayer AG threatened to stop making a fourth anti-HAT drug, suramin, leaving a growing number of patients in Africa bereft of treatment for their disease after the three-year stock ran out.

Anticipating the calamity, health agencies such as the World Health Organization (WHO) and the Centers for Disease Control and Prevention, and non-governmental organizations

Médecins Sans Frontières (MSF) and Epicentre, began looking for a way to persuade pharmaceutical companies not only to resume production, but to provide the drugs free or below cost. Jean Jannin of WHO's Department of Communicable Disease Surveillance and Response in Geneva, was instrumental in the lobbying effort. "We established a special network to try to find a solution. The first step was to have Aventis give WHO a license and transfer the technology to produce the drug."

But there were two problems: WHO and MSF are not drug manufacturers, and because eflornithine is difficult and expensive to make, alternate producers were not easy to find. Second, availability of drug in itself was not enough. Equally important were surveillance and screening, training of health workers and rehabilitation of clinics.
It was with the appearance of Vaniqa that a solution began to take shape. As Aventis was threatening to drop its panel of HAT drugs, BMS was examining new uses for failed drug candidates and found that DFMO in a cream preparation enabled hirsute women to eradicate facial hair. Topical application eased the problems of administration in a resource-poor setting and existing production facilities could be used as the source. Jannin's group persuaded BMS to donate the drug for five years, and additional lobbying triggered Aventis and Bayer to continue producing the other HAT drugs, and donate US $\$ 5$ million a year for five years for monitoring, treatment and research and development.

The result is current widespread access to a much-needed drug. 55 million people are exposed to HAT in 36 countries, with only 4 million of those under surveillance. There are half a million new cases a year, with perhaps 60,000 deaths, according to estimates by the World Health Organization (WHO). By contrast, the rate of disease in 1960 was 1 or 2 per 10,000.

Potter Wickware, San Francisco

\title{
Lifestyle drug market booming
}

Lifestyle drugs-medicines that treat conditions associated with lifestyle such as weight-loss tablets, anti-smoking agents, impotence therapies and hair restorersare now a major research and development area for the pharmaceutical industry. In fact, companies have invested over $\$ 20$ billion in research into such drugs since the 1990s. The reason why is clear: the market lifestyle for drugs is forecast to rise to over $\$ 29$ billion by 2007 from its current $\$ 20$ billion.

The market is driven predominantly by Western countries, where an image-conscious, aging society is prepared to pay high prices for compounds that promise to slow the aging process, improve mental agility, reduce weight gain and rejuvenate sexual function.

Perhaps the first lifestyle drugs were Viagra for erectile

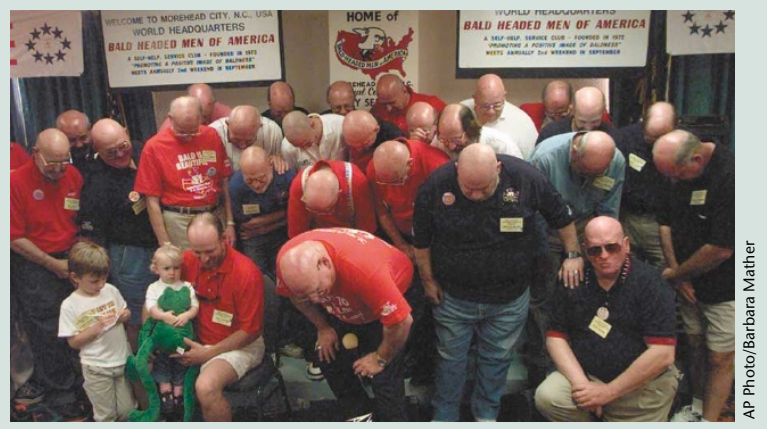
dysfunction (ED) and the anti-depressant, Prozac, whereas newer products include the anti-wrinkle agent, Botox. Although the sector is far from saturated, competition is already tight. For example, in the area of ED, new products include Abbot's Uprima (apomorphine), which was launched in Europe in May 2001, and Lilly ICOS's Cialis (tadalafil), which is expected to receive marketing authorization in the EU later this year. Both are considered to offer advantages over current therapies such as faster onset of action and duration of efficacy and will undoubtedly cannibalize Viagra's share of the ED market-worth an estimated $\$ 2$ billion in 2001.

Weight-loss drugs also represent a potentially large and profitable market as only two prescription medicines are currently available (Xenical and Reductil/Meridia). Novel products such as Regeneron's Axokine and Phytopharm's P57 are expected to show great promise as new and efficacious anti-fat drugs. Pharmaceutical companies will doubtless be showing keen interest in newly discovered properties of the leukemia drug, Geevec. Apparently the compound restores color to gray hair (NEJM 347, 446; 2002).

In other areas of lifestyle drugs, smoking cessation drugs include GlaxoSmithKline's GW468816 (glycine receptor), which is currently in phase 1 trials, and Roche's Tempium (lazabemide) in phase 3 trials. GlaxoSmithKline's Zyban (bupropion) is currently the only available drug to assist in smoking cessation and had sales of $\$ 174 \mathrm{~m}$ in 2000 . For full details see www.reutersbusinessinsight.com.

TiM ATKINSON, LONDON 